\title{
A GARANTIA AO ACESSO À INFORMAÇÃO E À TRANSPARÊNCIA DA ADMINISTRAÇÃO PÚBLICA FRENTE AO DIREITO DO CIDADÃO
}

\author{
Guarantee of access to information and transparency of public \\ administration against the citizen's right
}

\author{
Simone Paula Vesoloski ${ }^{1}$; Josieli Fátima Vesoloski²; Evandro Luis Dezordi ${ }^{3}$
}

\begin{abstract}
${ }^{1}$ Graduanda do curso de Direito da Universidade Regional Integrada do Alto Uruguai e das Missões URI Erechim. E-mail: simonels17@hotmail.com

${ }^{2}$ Graduada do curso de Agronomia, Mestranda do Curso de Engenharia de Alimentos da Universidade Regional Integrada do Alto Uruguai e das Missões - URI Erechim.E-mail: josy_vesoloski@hotmail. com

${ }^{3}$ Graduado em Ciências Jurídicas e Sociais. Especialista em Direito Constitucional. Professor na Universidade Regional Integrada do Alto Uruguai e das Missões - URI Erechim.E-mail: dezordi@ uricer.edu.br
\end{abstract}

RESUMO: O presente artigo objetivou destacar a importância acerca da transparência na administração pública, que se dá por meio da divulgação de informações fornecidas pelos municípios, com ênfase na análise da distinção e a verossimilhança da Lei da Transparência ${ }^{0}$ 131/2009 e a Lei de Acesso à Informação $n^{\circ} 12.527 / 11$. A metodologia utilizada compreendeu o raciocínio indutivo, analítico-descritivo, com técnica de pesquisa bibliográfica e pesquisa documental. Quanto à transparência na administração pública, refletiu-se sobre conexão e diferença entre a Lei da Transparência e a Lei de Acesso à Informação, além de perscrutar as possibilidades que perfectibilizam o controle social por meio de uma sociedade organizada e participativa, retratando a atuação, a corroboração e o compromisso do Tribunal de Contas do Estado do Rio Grande do Sul em efetivar as respectivas leis.

Palavras-chave: Administração Pública. Controle Social. Sociedade. Transparência. 


\begin{abstract}
The aim of this article was to highlight the importance of public administration transparency through the disclosure of information provided by the municipalities, with emphasis on the analysis of the distinction and likelihood of the Transparency Law No. 131/2009 and the Law on Access to Public Information. No. 12,527 / 11. The methodology used comprised the inductive reasoning, analytical-descriptive, with bibliographic research technique and documentary research. Regarding transparency in public administration, the connection and difference between the Transparency Law and the Access to Information Law were reflected, as well as the possibilities that make social control through an organized and participative society possible, portraying the performance, corroboration and commitment of the Court of Auditors of the State of Rio Grande do Sul to enforce the respective laws.
\end{abstract}

Keywords: Public Administration. Social Control. Society. Transparency.

\section{Introdução}

A administração pública representa o conjunto de órgãos e entes estatais que produzem bens, serviços e utilidades para a população, englobando uma série de atividades, atuações do Estado em prol da sociedade.

Para que o Estado se desenvolva, passando a fomentar e fornecer meios de satisfazer os anseios e as necessidades da coletividade, precisa, imprescindivelmente, que a administração pública seja estruturada, planejada, controlada, e também fiscalizada, pois para o desenvolvimento das atividades, por meio de seus órgãos e serviços, necessita de recursos públicos para concretizar as demandas e as perspectivas esperadas pela população. Nesse viés, além da eficiência e sensibilização na tomada de decisões, a transparência e o controle social se tornam aliados imprescritíveis nesse contexto social.

A presente pesquisa tem o intuito de trazer fundamentos e fazer uma análise da significância da transparência na administração pública como uma ferramenta facilitadora para concretizar o controle social nas atividades do Estado. Pretende-se verificar a distinção e semelhança entre a Lei Complementar $n^{\circ}$ 131/2009 da Transparência e a Lei do Acesso à Informação $\mathrm{n}^{\circ} 12.527 / 11$, que garantem o acesso às informações públicas, verificando-se como elas auxiliam no controle social.

Por ora, a administração pública é apontada e tem sido alvo de controvérsias e questionamentos quando o assunto trata dos atos, dos recursos e investimentos do dinheiro público, a respeito da transparência que se dá e a própria aplicabilidade dos recursos arrecadados no momento em que se decide onde aplicar.

A sociedade está cada vez mais participativa e cobra visibilidade do Estado, exigindo, além da qualidade, uma atuação satisfatória de seus representantes a fim de garantir a democracia, a cidadania e fiscalizar as despesas públicas. Neste contexto, é válido ressaltar que o acesso à informação pública deve ser evidenciado como um direito fundamental e inerente de cada cidadão brasileiro.

Diante de tal situação, verifica-se que o acesso à informação é crucial e fundamental. Além de possibilitar o conhecimento, vem 
alargar as formas de participação política, visando estimular a comunicação horizontalizada entre os indivíduos e o governo. Por consequência, espera-se que o cidadão exerça o seu papel ativista e desempenhe a função de acompanhar e fiscalizar, cobrando dos administradores meios de possibilitar uma gestão transparente, justa e célere.

Ao mencionar gestão de recursos públicos, vislumbra-se a necessidade de avaliar, conhecer e verificar como são empregados os recursos, o dinheiro do povo em prol do próprio povo, delineando uma forma de repensar como a transparência se coloca frente às ações executadas pelo Estado e como serão fornecidas as informações que levarão o conhecimento à sociedade.

Todo o tema que envolve a administração pública e a relação dos administradores versus administrados é relevantemente importante e merece aprofundamento. Diante disso, justifica-se que a pesquisa deste trabalho propõe conhecer a legislação em vigor, frisar diferenças e semelhança entre as leis vigentes e elencar o papel do cidadão como ator da democracia e do controle social.

Desse modo, o conteúdo que tange a pesquisa foi realizado em livros, artigos, dissertações e sites relacionados ao tema, utilizando o método analítico-descritivo. Este artigo, além desta introdução, expõe uma síntese em relação à transparência na administração pública, tratando-se da diferenciação e verossimilhança entre a Lei da Transparência e a Lei da Informação. Por fim, traz-se a menção da transparência da administração pública elencando o controle social e as ferramentas para efetivação, também se retrata a participação e contribuição que o Tribunal de Contas do Estado do Rio Grande do Sul (TCE-RS) assumiu e continua assumindo para garantir o amplo acesso às informações de acordo com as exigências legais.

\section{A Transparência Formalizada na Esfera da Administração Pública}

A administração pública é uma atividade de alta relevância, pois é dela que se constrói um alicerce estruturado para facilitar o crescimento e o desenvolvimento da sociedade. Nesse contraponto, é importante mencionar, em relação aos princípios da legalidade, impessoalidade, moralidade, publicidade e eficiência, que devem nortear e serem efetivados nas atividades e decisões que a administração pública toma com finalidade do interesse público, princípios estes que estão previstos no caput do art. 37 da Constituição da República Federativa do Brasil: "A administração pública direta e indireta de qualquer dos Poderes da União, dos Estados, do Distrito Federal e dos Municípios obedecerá aos princípios de legalidade, impessoalidade, moralidade, publicidade e eficiência e, também, ao seguinte [...]" (BRASIL, 1988). Nesta senda, a administração pública é "“...] todo aparelhamento do Estado preordenado à realização de serviços visando à satisfação das necessidades coletivas." (MEIRELLES et al., 2016, p. 68).

Uma administração transparente permite que o cidadão tenha conhecimento dos assuntos que permeiam a gestão em prol da coletividade, o investimento e a aplicação dos recursos púbicos, ciência dos gastos e, diante disso, é fundamental ter facilidade ao acesso destas informações, bem como saber interpretar e compreender tais informações.

Um dos aparatos jurídicos para embasar e frisar que as informações devam ser claras, e qualquer pessoa ter o direito de ter acesso a elas, está previsto na Constituição Cidadã de 1988, art. $5^{\circ}$, inciso XXXIII:

XXXIII - todos têm direito a receber dos órgãos públicos informações de seu interesse particular, ou de interesse coletivo ou 
geral, que serão prestadas no prazo da lei, sob pena de responsabilidade, ressalvadas aquelas cujo sigilo seja imprescindível à segurança da sociedade e do Estado. (BRASIL, 1988).

Nesta concepção, é inegável mencionar que, na previsão contida na Constituição promulgada em 1988, o constituinte teve boa intenção, mas esta acessibilidade às informações dos órgãos públicos só se tornaria possível após a criação de uma lei que regulamentasse essa demanda, e isto se sucedeu apenas em 2011, com a promulgação da Lei $n^{\circ} 12.527 / 11$, que regula o acesso a informações previsto no inciso mencionado anteriormente.

Nesta senda, segue o entendimento de Cardon:

Ao se ampliar na internet, o espaço público aspira à sociabilidade, à vida privada e à expressividade dos indivíduos. Torna ainda mais transparente os bastidores da vida social, das opiniões dos internautas e dos dados de administração. Mesmo se as fronteiras entre esses universos estão longe de terem desaparecido, a divisão entre o mundo público e o mundo privado parece menos evidente. A web revela uma cena na qual a sociedade se representa, compartilhando informações que até então jamais eram apresentadas. A sociedade democrática sai da órbita representativa. (CARDON, 2012, p. 106).

A Lei complementar 131/2009 editou e acrescentou dispositivos à Lei de Responsabilidade Fiscal 101/2000, ressaltando o direito de qualquer pessoa, física bem como jurídica, poder ter acesso à informação, obrigando todos os Entes a ter um portal de transparência com informações atualizadas sobre a execução orçamentária e financeira. $\mathrm{O}$ art. $2^{\circ}$ da lei complementar 131/2009 refere-se à explicação que segue transcrita a seguir:
Art. $2^{\circ}$ A Lei Complementar $\mathrm{n}^{\circ} 101$, de 4 de maio de 2000, passa a vigorar acrescida dos seguintes arts. 48-A, 73-A, 73-B e 73-C:

"Art. 48-A. Para os fins a que se refere o inciso II do parágrafo único do art. 48, os entes da Federação disponibilizarão a qualquer pessoa física ou jurídica o acesso a informações referentes a:

I - quanto à despesa: todos os atos praticados pelas unidades gestoras no decorrer da execução da despesa, no momento de sua realização, com a disponibilização mínima dos dados referentes ao número do correspondente processo, ao bem fornecido ou ao serviço prestado, à pessoa física ou jurídica beneficiária do pagamento e, quando for o caso, ao procedimento licitatório realizado;

II - quanto à receita: o lançamento e o recebimento de toda a receita das unidades gestoras, inclusive referente a recursos extraordinários." (BRASIL, 2009).

A Lei ${ }^{\circ}$ 12.527/11 (BRASIL, 2011) veio em resposta à lacuna constitucional, passando a conter dispositivos e procedimentos com o intuito de garantir o acesso às informações, que até pouco tempo antes eram inacessíveis e desconhecidas pelos cidadãos. $\mathrm{O}$ art. $3^{\circ}$ da mencionada lei assegura o direito definindo alguns parâmetros:

Art. $3^{\circ}$ Os procedimentos previstos nesta Lei destinam-se a assegurar o direito fundamental de acesso à informação e devem ser executados em conformidade com os princípios básicos da administração pública e com as seguintes diretrizes:

I - observância da publicidade como preceito geral e do sigilo como exceção;

II - divulgação de informações de interesse público, independentemente de solicitações; 
III - utilização de meios de comunicação viabilizados pela tecnologia da informação;

IV - fomento ao desenvolvimento da cultura de transparência na administração pública;

$\mathrm{V}$ - desenvolvimento do controle social da administração pública. (BRASIL, 2011).

A força destas duas leis, juntamente com a previsão contida na Constituição, garante, assegura e ratifica que o poder púbico, representado por todos os Entes, criem alternativas, tecnologias por meio de portais e divulguem ativamente dados relativos a sua administração, objetivando o acompanhamento social, para que tal conteúdo possa ser acessado por um único cidadão apenas ou de modo coletivo, inclusive reforçando que este direito às informações independe de solicitação.

Apesar de se ter esse amparo legal, para Melo; Fuchigami (2019), a transparência ainda representa um "gargalo" da própria lei, pois a obrigatoriedade resulta e depende da proatividade das instituições públicas, em vista de não se ter um padrão de especificação nas informações a serem prestadas, inexiste de fato um cumprimento efetivo do aparato legal em questão, pois fica a mera deliberalidade de cada ente público.

Nesse sentido, os referidos autores, citados no parágrafo anterior, apontam que as informações obtidas nos sítios públicos e eletrônicos do nosso país, muitos municípios estão com informações indisponíveis, incompletas e até mesmo incompreensíveis.

Sendo assim, é inegável que o desenvolvimento da sociedade é um fator que modifica e a torna mais participativa e democrática, bem como o acesso à informação rompe barreiras e traz um mundo aberto e acessível a todos. O uso da tecnologia traduz outra dimensão social, que emancipa a coletividade, abrindo uma nova fronteira, a partir de então tornando os bastidores públicos um lugar de acesso irrestrito. Contudo, este comprometimento com o cumprimento legal deve partir tanto do poder público quanto de cada cidadão. Ter um compromisso com o fornecimento de informações verídicas e de fácil compreensão fomenta uma administração pública mais horizontalizada e próxima da sociedade.

\section{A Lei da Transparência versus a Lei da Informação na Efetivação do Direito}

Na democracia comunicativa, a Lei da Transparência $n^{\circ} 131 / 2009$ e a Lei de Acesso à Informação $\mathrm{n}^{\circ} 12.527 / 2011$ contribuem para uma relação mais democrática entre governo e sociedade. Neste contexto, Piaia e outros (2017) salientam que o acesso à informação pública deve ser tratado como um direito inerente a cada pessoa, decorrendo do exercício da cidadania: "[...] o acesso público a informações oficiais é o corolário da transparência na prestação de contas públicas, fazendo com que o direito à informação esteja amplamente ligado com o princípio da transparência" (ZBOROWSKI et al., 2015 , p. 222). Desse modo, proporcionando a qualquer pessoa o acompanhamento e o conhecimento do exercício da administração pública.

No ordenamento jurídico existe uma diferenciação entre as duas leis citadas, quanto ao fornecimento de informações e que não podem ser confundidas; elas abrangem questões distintas, porém, para que cada Ente exerça de forma clara a publicidade e as obrigações com a sociedade, ambas precisam ser cumpridas em conjunto.

Por ora, cabe mencionar que a Lei da Transparência foi criada para auxiliar na divulgação da receita e das despesas de todo o ente público, órgão, sob a fiscalização do 
Ministério Público. Receitas e despesas em tempo real e disponibilizadas em um sítio na internet, demonstrando, por exemplo, o valor da despesa, liquidação e pagamento, classificação orçamentária, natureza da despesa, lançamento da receita, arrecadação, recursos extraordinários e assim por diante. (BRASIL, 2009).

Já a Lei de Acesso à Informação (BRASIL, 2011) trata a respeito das informações públicas, permitindo que qualquer cidadão interessado e sem quaisquer justificativa solicite documentos ao Ente ou ao órgão público, e fornecendo, por meio de um sítio na internet, informações a respeito das competências, funções, estrutura organizacional, convênios, repasses e transferências de recursos financeiros, execução orçamentária e financeira, divulgação de licitações e contratos realizados, ações e programas implementados.

Estas leis contribuem para aumentar a eficiência do poder público, da administração, minimizar a corrupção e elevar o índice de participação social, e tem como lema fundamentado que o acesso à informação é um direito de todo o cidadão e um dever do Estado, deste modo "[...] o direito a informação é considerado um princípio fundamental, uma vez que proporciona o controle da atuação estatal.” (ZBOROWSKI et al., 2015, p. 222).

Para Silva; Hoch; Righi (2013), somente a tecnologia não será capaz de produzir efeitos positivos e desejados se não estiver amparada por uma postura transformadora e engajada por parte da administração pública, que não devem apenas compreender a importância de garantir o acesso aos dados de interesse público, mas reconhecer, acima de tudo, que o cidadão está legitimado a obter essas informações, bem como tem o direito de exigir esse cumprimento legal, exercer o controle social, apresentar e cobrar demandas, além de receber respaldo dessas exigências. Essas prerrogativas apontam um empoderamento dos atores sociais.

Nesta senda, Monteiro (2006) acredita que a partir da inserção e ativismo dos cidadãos no cumprimento dessas leis, o governo se torna mais participativo, mais transparente nos comportamentos políticos-legisladores e de execução. Essa mudança de postura para concretizar uma administração pública exige uma reforma de diferentes abrangências, começando pelo cidadão, pelos entes públicos, órgãos do executivo, servidores, enfim, todos que fazem a administração pública funcionar.

Nesse sentido, é importante que a administração pública, os gestores e servidores públicos se conscientizem de que estão para servir o povo, e não “fazer favores”. A transparência pública e a garantia de acesso às informações são prerrogativas legais e direitos que devem ser preservados sem obscurações ou empecilhos.

\section{A Transparência da Administração Pública e as Ferramentas de Efetivação do Controle Social}

Percebe-se, assim, que a administração pública tem buscado alternativas, meios de se adequar às necessidades da sociedade a fim de viabilizar e possibilitar que as pessoas possam participar das decisões de modo mais democrático. (ZBOROWSKI et al., 2015). Com isso, certifica-se que o uso da tecnologia pode e deve projetar a sociedade em um contexto elevado, em que a administração pública pode se demonstrar mais transparente e propiciando benefícios à sociedade, propagando a atuação dos administradores e o desenvolvimento da democracia e meios de controle social.

Na busca dos anseios coletivos, o controle social sintetiza a integração da sociedade com a própria administração pública, com a função de solucionar os problemas e as 
deficiências sociais, sendo exercido por meio da efetivação dos direitos previstos na constituição, como o direito de indagar a legitimidade, questionar as contas públicas em qualquer espera e, como consequência, direito de denunciar irregularidades evidenciadas ou ilegalidades identificadas perante o Tribunal de Contas da União. (MATTE et al., 2012).

Di Pietro (1988) ressalta que o controle social funciona somente se a sociedade estiver conscientizada de que tem o direito de participar desse controle, enfatizando que o poder público deve criar instrumentos e divulgar para que esta participação esteja ao alcance de qualquer cidadão. Ainda menciona que, enquanto o controle social não fizer parte da cultura da população, o direito fica inerte.

Com vista nessa participação, no controle social, Oliveira (2006) tem a percepção que a participação pública mais ativa e participativa requer planejamento. É um processo que não nasce do dia para a noite, porém, gradativamente, leva a cultura democrática de participação do cidadão a um patamar diferenciado. Criar métodos de planejamento com o viés voltado para a sensibilização à participação, ao acesso às informações públicas, ao controle social, deve ser levado em conta e servir como um ponto de partida capaz de articular as relações da sociedade no contexto público em busca do seu bem comum.

Atualmente, são diversas as ferramentas que possibilitam ao cidadão concretizar a efetivação do controle social. O conselho de política pública, observatório social, orçamento participativo, audiência pública e ouvidoria são exemplos de como a sociedade pode contribuir para efetivar seus direitos, mostrar a cara e não calar as vozes, interagindo com o poder púbico, fiscalizando e fortalecendo o espaço de controle social e o direito à participação na gestão.

Contudo, Cruz; Silva e Spinelli (2016) apontam que para proporcionar o devido acesso e cumprimento legal, vários fatores são essenciais para compactuar com essa perfectibilização. A ampliação e a melhoria dos serviços públicos são tidas como um fator crucial e de grande valia, bem como o combate à corrupção, o estímulo à promoção da transparência e facilidade no acesso dessas informações. Sistemas de controle internos se tornam bons aliados para colaborar com essas demandas e manter um diálogo facilitado e permanente entre administração pública e a sociedade.

Oliveira; Ramielli (2014) ressaltam que ainda existem muitas melhorias a serem feitas em relação à perspectiva de um governo eletrônico democrático, ao acesso e à transparência almejada. A construção desse caminho é positiva e aponta a direção para reafirmar uma conexão horizontal entre governo e cidadão, para, de fato, perfectibilizarem um Estado Democrático de Direito.

Dessa forma, o cidadão tem o direito de saber como a administração pública está investindo e gastando o dinheiro, e, por consequência, através do controle social, tem o direito e dever de influenciar e participar do processo decisório no tocante ao interesse da coletividade.

\section{O Tribunal de Contas do Estado do Rio Grande do Sul e a Responsabilidade com a Efetividade da Lei da Transparência e a Lei de Acesso à Informação}

No Brasil, de acordo com dados históricos, o Tribunal de Contas da União foi instituído em 1891. Porém, o estado do Rio Grande do Sul criou seu Tribunal de Contas em 1935. Com o passar dos anos e frente às mudanças no contexto social, o posicionamento do Tribunal de Contas do Estado do 
Rio Grande do Sul (TCE-RS) vem ganhando novo formato, assumindo o compromisso para garantir o amplo acesso às informações, acreditando que isso implica na maior oportunidade do controle social e institucional, proporcionando maior participação popular e, por consequência, uma gestão pública eficiente.

Em razão disso (MATTE et al., 2012), o TCE-RS, com o propósito de melhor orientar e incentivar que todos os membros do poder executivo e legislativo fomentem a informação em cada município gaúcho, vem desenvolvendo, desde 2012, uma análise do conteúdo dos portais dos municípios gaúchos, quanto ao atendimento às exigências da Lei de Acesso à Informação ${ }^{\circ} 12.527 / 2011$ e da Lei da Transparência $n^{\circ} 131 / 2009$. Por conseguinte, disponibiliza, em seu sítio eletrônico, uma cartilha prática, didática e de fácil compreensão, elaborada com orientações pautadas nas referidas leis.

A pesquisa que o TCE-RS faz com os municípios gaúchos abrange os 497 municípios do estado e segue, como parâmetro, preceitos previstos na Constituição da República Federativa do Brasil, e nas leis mencionadas nesta pesquisa, entendendo que é dever de cada município prestar todas as informações de interesse coletivo ou geral por ele produzidas ou custodiadas. (MATTE et al., 2012).

Pelo exposto, é relevante citar que o TCE-RS, por meio de seus auditores, acessam individualmente todos os sites dos executivos e legislativos municipais gaúchos, tal como um cidadão faria, adotando critérios que são analisados pelo preenchimento de um questionário padrão elaborado com base nas exigências legais.

Como afirmado (MATTE et al., 2012), desde 2012 este trabalho vem sendo realizado, e, em contrapartida, os auditores do TCE-RS comunicam a todos os prefeitos, presidentes de câmaras e responsáveis pelo controle interno municipal acerca do resultado da pesquisa realizada, apontando possíveis correções, revisão da avaliação por discordância de alguma informação relevante que deveria ser disponibilizada, aprazando data para realizarem as reanálises solicitadas, alterando ou acrescentando informações.

Por fim, o TCE-RS destaca que, no decorrer dos anos, sua atuação visa a alcançar a adesão de práticas de transparência pelos municípios gaúchos, e percebe que, gradativamente, houve avanços significativos não apenas nos índices de atendimento à legislação vigente, mas no fortalecimento da cultura da transparência dos registros municipais. Porém, apesar desse avanço, ressalta que ainda existem necessidades e pontos de melhoria.

Nesse diapasão, para Melo e Fuchigami (2019), o poder público e os cidadãos devem se conscientizar e atuar em conjunto e em prol de divulgar/praticar e cobrar uma cultura de transparência permanente em todos os âmbitos da sociedade. Essa transformação deve ser progressiva, constante e participativa.

Para Abrucio (2007), garantir a transparência é um instrumento de grande potencial capaz de elevar a eficiência governamental no país. Muito se avançou nesse quesito, contudo, ainda há órgãos “avessos" à transparência. Não basta apenas tornar transparente o momento de apresentar os dados, as estatísticas; é necessário garantir e permitir o acesso e a transparência em todos os momentos, inclusive em tempo real.

A todas as pessoas - seja cidadão da sociedade democrática de direito, seja por parte dos gestores (poder público) - deve haver uma sincronia e reconfirmação dos princípios que emergem e emanam a atuação da administração pública, fazendo valer direitos e garantias. Essa ideia deve ser precursora e mantenedora de uma administração centrada no povo e voltada para a verdadeira democracia. 


\section{Considerações Finais}

A partir da investigação desta pesquisa, foi possível verificar que houve avanço para que a administração pública tornasse mais acessíveis as informações e o próprio legislador em fortalecer a transparência por meio de legislações.

Notadamente, formar um cidadão participativo não é uma tarefa fácil nem imediata. As ferramentas para acesso às informações estão disponíveis, porém falta interesse, conhecimento e até mesmo vontade em exercer e usufruir deste direito. É necessário que cada cidadão se envolva mais com os interesses coletivos, saindo da "zona de conforto", tornando-se protagonista e incentivando que outras pessoas também possam assumir o papel e juntos buscar o equilíbrio e o controle social, com viés na participação das decisões, estreitando laços entre administradores e administrados.

Ante o exposto, é necessário reconhecer que os portais garantem meios de demonstrar a transparência da administração pública e são fundamentais para reconhecer o direito que cada cidadão tem de saber como está a execução da administração.

Entretanto, diante da crescente evolução tecnológica, cabe destacar que, apesar de uma grande parte da população ter acesso e fazer o uso da internet, muitos cidadãos ainda não se encontram inseridos neste mundo digital, sendo excluídos da participação efetiva de controle social. Nessa senda, de acordo com dados e pesquisa do Instituto Brasileiro de Geografia e Estatística (IBGE), realizada em 2017, o país possui em média 126,3 milhões de pessoas conectadas, correspondendo a $69,9 \%$ da população com idade acima de 10 anos, sendo que uma parcela expressiva da população ainda não tem acesso à internet.
Contudo, o papel que o TCE-RS assume frente ao estímulo para que aconteça a efetiva divulgação das informações pelos municípios gaúchos é muito importante para a população, pois reforça sua missão e o seu propósito, exercendo, atuando e contribuindo para o aperfeiçoamento da administração pública, gerando impacto e propiciando o desenvolvimento humano e institucional.

Neste contraponto, a administração pública deve, de modo contínuo, promover, por meio de todos os métodos de divulgação, ferramentas para proporcionar o conhecimento da população e fazer com que, por exemplo, o Conselho de Política Pública, observatório social, orçamento participativo, audiência pública e ouvidoria, que são ferramentas de participação e controle social, sejam conhecidas e as reuniões ocorram em dias e locais acessíveis para que a maior parte da população interessada possa participar e contribuir com a democracia e interação social.

Controle social não é um assunto novo. Diante disso, é notável que os meios e ferramentas de efetivação são diversos e pouco conhecidos pela sociedade, e a consequência de tal fato traduz a teoria do desconhecido, dificultando a plena utilização. A articulação da sociedade em se tornar mais participativa requer mudança de postura, chamando o interessado a despertar quanto à importância de conhecer e exercer seus direitos, e quanto mais informada uma sociedade, mais participativa se torna, facilitando que a engrenagem pública ganhe uma nova forma e refletindo o anseio da coletividade.

O fortalecimento dos instrumentos de participação da sociedade depende do discernimento individual de cada cidadão em digerir a importância dessa participação. Verifica-se que o papel da escola é fundamental em esclarecer e colocar à disposição informações a respeito de como se efetiva a participação social, a democracia, a cidadania e o controle 
social, pois essas ações proporcionarão que a formação dessas crianças e adolescentes os tornem adultos participativos, conhecedores e envolvidos com os assuntos de interesse coletivo.

Conclui-se que sem transparência o controle social não existe. $\mathrm{O}$ acesso às informações do poder público e a compreensão destas é o ponto de partida para a transparência efetiva. Ressaltando que o controle social é a participação ativa de cada cidadão na gestão pública, sendo o principal mecanismo para fortalecer a cidadania, a democracia e os direitos de cada pessoa, diminuindo a lacuna entre a sociedade e o Estado.

\title{
REFERÊNCIAS
}

\begin{abstract}
ABRUCIO, F. L. Trajetória recente da gestão pública brasileira: um balanço crítico e a renovação da agenda de reformas. Disponível em: https://www.scielo.br/scielo.php?script=sci arttext\&pid=S0034-76122007000700005\&lang=pt. Acesso em: 20 maio 2020.
\end{abstract}

BRASIL. Constituição da República Federativa do Brasil de 1988. Texto constitucional promulgado em 5 de outubro de 1988. Disponível em: http://www.planalto.gov.br/ccivil_03/ Constituicao/Constituicao.htm. Acesso em: 30 jun. 2019.

BRASIL. Lei Complementar $\mathbf{n}^{\circ}$ 131/2009 - Lei da Transparência. Acrescenta dispositivos à Lei Complementar $n^{\circ} 101$, de 4 de maio de 2000, que estabelece normas de finanças públicas voltadas para a responsabilidade na gestão fiscal e dá outras providências, a fim de determinar a disponibilização, em tempo real, de informações pormenorizadas sobre a execução orçamentária e financeira da União, dos Estados, do Distrito Federal e dos Municípios. Diário Oficial da União: República Federativa do Brasil, DF, 25 maio 2009. Disponível em: http://www.planalto.gov.br/ ccivil_03/leis/LCP/Lcp131.htm. Acesso em: 30 jun. 2019.

BRASIL. Lei de Acesso à Informação - LAI, n⿳ 12.527, de 18 de Novembro de 2011. Regula o acesso a informações previsto no inciso XXXIII do art. $5^{\circ}$, no inciso II do $\S 3^{\circ}$ do art. 37 e no $\S 2^{\circ}$ do art. 216 da Constituição Federal; altera a Lei $n^{\circ}$ 8.112, de 11 de dezembro de 1990; revoga a Lei $\mathrm{n}^{\circ}$ 11.111, de 5 de maio de 2005, e dispositivos da Lei $\mathrm{n}^{\circ} 8.159$, de 8 de janeiro de 1991; e dá outras providências. Diário Oficial da União: República Federativa do Brasil, DF, 18 nov. 2011. Disponível em: http://www.planalto.gov.br/ccivil_03/_ato2011-2014/2011/lei/112527.htm. Acesso em: 30 jun.. 2019.

CRUZ, M. do C. M. T.; SILVA, T. A. B.; SPINELLI, M. V.. O papel das controladorias no cumprimento da Lei de Acesso à informação pelos municípios brasileiros. Disponível em: https:/www.scielo.br/scielo.php?script=sci_arttext\&pid=S167939512016000300721\&lang=pt. Acesso em: 18 maio 2020.

Dados referente a: Acesso a Internet e a Televisão e posse de telefone móvel celular para uso pessoal - PNAD contínua. Disponível em: https://biblioteca.ibge.gov.br/visualizacao/livros/ liv101631_informativo.pdf. Acesso em: 08 jul. 2019.

Dados referente a: Lei da Transparência. Disponível em: http://www.leidatransparencia.cnm.org. br/. Acesso em: 30 jun. 2019.

Dados referente a: Lei de acesso a Informação. Disponível em:http://www.acessoainformacao.gov. br/central-de-conteudo/infograficos/arquivos/entenda-a-lai/noticias. Acesso em: 30 jun. 2019.

DI PIETRO, M. S. Z. A defesa do cidadão e das res pública. Revista do Serviço Público, ano 49, nº 02, abr./jun. 1998. Disponível em: www.enap.gov.br. Acesso em: 17 fev. 2019. 
Entenda a diferença entre a Lei da Transparência e a Lei de Aceso à Informação. Disponível em: http://sisgov.com/transparencia-acesso-informacao/. Acesso em: 08 jul. 2019.

MATTE, A. da C.; ASSMANN, C.; HOMERCHER, E. T. Análise dos sítios dos poderes e órgãos constitucionais do Estado o Rio Grande do Sul conforme disposições da lei de acesso à informação. In: Transparência nos portais, Brasil, RS, 2012 - 2017. Disponível em: http://www1.tce. rs.gov.br/portal/page/portal/tcers/publicacoes/estudos/avaliacao_portais_rs. Acesso em: 08 jul. 2019.

MEIRELLES, H. L.; BURLE FILHO, J. E. Direito Administrativo Brasileiro. 42. ed. São Paulo: Malheiros Editores Ltda., p. 63-69, 2016.

MELO, D. A.; FUCHIGAMI, H. Y. Proposta de índice bidimensional de transparência da informação público-eletrônica como ferramenta para participação e controle sociais. Disponível em: https://www.scielo.br/scielo.php?script=sci_arttext\&pid=S141323112019000200179\&lang=pt. Acesso em: 18 maio 2020.

MONTEIRO, J. V. Intermediação política, transparência decisória e atendimentos preferenciais. Disponível em: https://www.scielo.br/scielo.php?script=sci_arttext\&pid=S0034$76122006000400012 \&$ lang=pt. Acesso em: 20 maio 2020.

OLIVEIRA, J. A. P.de. Desafios do planejamento em políticas públicas: diferentes visões e práticas. Disponível em: https://www.scielo.br/scielo.php?script=sci_arttext\&pid=S0034$76122006000200006 \&$ lang=pt. Acesso em: 20 maio 2020.

OLIVEIRA, R. S. de; RAMIELLI, F. P. O direito ao acesso à informação na construção da democracia participativa: uma análise da página do conselho nacional de justiça no Facebook. Disponível em: https:/www.scielo.br/scielo.php?script=sci_arttext\&pid=S217770552014000200007\&lang=pt. Acesso em: 20 maio 2020.

PIAIA, T. C.; CEZARO, B. de. ZIEGLER, J. A. A proteção da cidadania no acesso à internet e à informação no Brasil. In: CERVI, J. R.; HAHN, N. B. (Org.) Diálogo e Entendimento: direito e multiculturalismo \& políticas de cidadania e resolução de conflito: tomo 8. Campinas, SP: Millennium Editora, 2017, p.199- 215.

SILVA, R. L. da; HOCH, P. A.; RIGHI, L. M. Transparência Pública e a atuação normativa do CNJ. Disponível em: https://www.scielo.br/scielo.php?script=sci_arttext\&pid=S1808$24322013000200005 \&$ lang=pt>. Acesso em: 18 maio 2020.

ZBOROWSKI, J.; ANGELIN, R. Direito Fundamental à informação nas compras públicas: Um mecanismo de efetivação da democracia no Brasil. In: DEL'OMO, F. de S.; CERVI, J. R.; VERONESE, O. (Org.) Multiculturalidade e cidadania: olhares transversais. Campinas, SP: Millennium Editora, 2015, p. 219-235. 
